\title{
Níveis de lisina digestível em dietas contendo ractopamina para suínos em terminação
}

\author{
Levels of digestible lysine in diets with ractopamine for finishing pigs
}

\author{
CORASSA, Anderson ${ }^{1 *}$; KIEFER, Charles ${ }^{2}$; NIETO, Viviane Maria Oliveira Santos ${ }^{2}$ \\ ${ }^{1}$ Universidade Federal de Mato Grosso, Instituto de Ciências Agrárias e Ambientatis, Sinop, Mato \\ Grosso, Brasil. \\ ${ }^{2}$ Universidade Federal de Mato Grosso do Sul, Faculdade de Medicina Veterinária e Zootecnia, \\ Deapartaemnto de Zootecnia, Campo Grande, Mato Grosso do Sul, Brasil. \\ *Endereço para correspondência: anderson_corassa@ufmt.br
}

RESUMO

Objetivou-se avaliar níveis de lisina digestível em dietas contendo $5 \mathrm{ppm}$ de ractopamina sobre o desempenho e características quantitativas de carcaça de suínos em fase de terminação. Foram utilizados 96 suínos, sendo 48 machos castrados e 48 fêmeas, com peso inicial de $83,57 \pm 4,07 \mathrm{~kg}$, distribuídos em delineamento inteiramente ao acaso, com quatro níveis de lisina digestível $(0,94 ; 0,96 ; 1,02$ e $1,04 \%)$, com três repetições de oito animais cada. $\mathrm{O}$ período experimental teve duração de 28 dias. O consumo de ração diário reduziu e a conversão alimentar melhorou linearmente de acordo com o aumento dos níveis de lisina digestível das dietas. Os pesos final, de frigorífico e de carcaça quente, o rendimento de carcaça, a quantidade de carne magra e o índice de bonificação aumentaram linearmente de acordo com o aumento dos níveis de lisina digestível. Não houve efeito dos níveis de lisina digestível sobre o ganho de peso diário, perda de peso durante o transporte e a porcentagem de carne magra da carcaça. Concluiu-se que, em dietas contendo 5ppm de ractopamina, o nível de $1,04 \%$ de lisina digestível melhora a conversão alimentar e aumenta o peso final, o peso e o rendimento de carcaça, a quantidade de carne magra e o índice de bonificação das carcaças dos suínos.

Palavras-chaves: aditivos, beta-adrenérgico, carne magra, carcaça

\section{SUMMARY}

The objective was to evaluate levels of digestible lysine in diets with $5 \mathrm{ppm}$ of ractopamine on performance and carcass characteristics of finishing pigs. Ninety-six pigs, 48 barrows and gilts with initial body weight of $83.57 \pm 4.07 \mathrm{~kg}$, were sorted in a complete randomized design with four levels of digestible lysine $(0.94 ; 0.96 ; 1.02$ e $1.04 \%)$, with three replications and eight animals each. The experimental period lasted 28 days. The feed intake was reduced and feed:gain ration improved linearly with increase digestible lysine levels in diets. Final, slaughter and hot carcass weights, carcass yield, amount of lean meat and payment index increase linearly with increase of digestible lysine levels. There was no effect of digestible lysine levels on daily gain, farm to slaughter shrink and lean meat percent. In conclusion, in diets with $5 \mathrm{ppm}$ ractopamine, $1.04 \%$ digestible lysine improve feed:gain ration and increase final weight, carcass weight and yield, amount of lean meat and payment index of carcass of pigs.

Keywords: additives, beta-adrenergic, carcass, lean meat

\section{INTRODUÇÃO}

A melhoria genética dos plantéis brasileiros tem exigido uma revisão nos níveis nutricionais e no manejo da 
alimentação, adaptando-os a nova realidade da produção e do mercado, caracterizada pela elevação do percentual de carne nas carcaças entre outros.

Mesmo com o aprimoramento do padrão genético dos suínos, muitos nutricionistas utilizam estratégias nutricionais para potencializar o desempenho $\mathrm{e}$ as características quantitativas das carcaças como os agonistas $\beta$ adrenérgicos. Dentre os $\beta$ adrenérgicos, a ractopamina promove diminuição da deposição de gordura e aumento da massa muscular da carcaça dos suínos, por meio de estímulos da lipólise e redução da lipogênese (MILLS, 2002; ARMSTRONG et al., 2004).

Porém, as alterações metabólicas causadas pela ractopamina podem interferir nas exigências nutricionais dos animais. As melhorias no desempenho estão diretamente relacionadas ao aporte de lisina digestível nas dietas, visto a estreita relação entre este nutriente e a deposição proteica (APPLE et al., 2004).

A deficiência em lisina ao usar-se ractopamina pode limitar a resposta animal, tendo em vista que este aminoácido é responsável pela síntese proteica e atua como fator de importância na qualidade da carcaça. $\mathrm{O}$ nível de lisina digestível nas dietas afeta a magnitude com que os suínos respondem a ractopamina (APPLE et al., 2004) e este fato evidencia a necessidade de se realizar ajustes nutricionais em função da utilização deste aditivo (MITCHELL et al., 1991). Em decorrência do aumento da síntese proteica gerada pela ractopamina, as recomendações disponíveis na literatura preconizam ajustes graduais de lisina de acordo com os níveis de inclusão e a duração da suplementação do aditivo (ROSTAGNO et al., 2011). Porém, o acréscimo percentual de lisina digestível em função da utilização da ractopamina varia entre os trabalhos. Estudos têm estabelecido acréscimos de até 30\% para o nível de lisina digestível em dietas suplementadas com 20ppm de ractopamina (PÉREZ et al., 2006; WEBSTER et al., 2007; PEREIRA et al., 2008; ALMEIDA et al., 2010).

Considerando que a ractopamina é um aditivo oneroso e aliado a necessidade de aumentos dos níveis de lisina em dietas suplementadas com ractopamina, podem tornar sua utilização inviável na prática. Neste sentido, realizou-se este estudo com o objetivo de avaliar níveis de lisina digestível em dietas contendo ractopamina para suínos em fase de terminação.

\section{MATERIAL E MÉTODOS}

O experimento foi conduzido em granja comercial, em Bom Jesus, SC. Foram utilizados 96 suínos, sendo 48 machos castrados e 48 fêmeas, com peso inicial de $83,57 \pm 4,07 \mathrm{~kg}$. Os animais foram alojados em galpão de alvenaria, com piso de concreto e coberto com telhas de amianto. Foram alocados em baias com área de $12,9 \mathrm{~m}^{2}(3,0 \mathrm{x}$ 4,3m), providas de bebedouros tipo chupeta e comedouros de madeira disposto à frente da baia.

Os animais foram distribuídos em delineamento inteiramente casualizado, com quatro níveis de lisina digestível $(0,94 ; 0,96 ; 1,02$ e $1,04 \%)$, com três repetições de oito animais cada. Cada unidade experimental foi composta com quatro machos e quatro fêmeas. $\mathrm{O}$ período experimental total foi de 28 dias.

As dietas experimentais (Tabela 1) foram formuladas de forma a suplantar as exigências nutricionais mínimas para suínos fêmeas de alto potencial genético 
e desempenho regular (ROSTAGNO et al., 2005). As dietas e a água foram fornecidas ad libtum durante todo o período experimental.

A temperatura e umidade, dentro das instalações, foram registradas por termômetro de máxima e mínima. O controle de temperatura, ventilação e concentração de gases no interior do galpão foi realizado por meio de manejo de cortinas e microaspersão nas linhas dispostas sobre as baias. Durante o período experimental a temperatura do ar registrada foi de $24,94 \pm 1,63^{\circ} \mathrm{C}$ e as temperaturas médias máximas e mínimas foram de $19,63 \pm 1,67^{\circ} \mathrm{C}$ e $30,24 \pm 2,28^{\circ} \mathrm{C}$, respectivamente.

Tabela 1. Composição das dietas experimentais na fase terminação contendo diferentes níveis de lisina digestível e suplementados com ractopamina. (Centesimal composition of experimental rations for finishing pigs with different levels of digestible lysine and supplemented with ractopamine)

\begin{tabular}{|c|c|c|c|c|}
\hline \multirow{2}{*}{ Ingredientes } & \multicolumn{4}{|c|}{ Níveis de lisina digestível(\%) } \\
\hline & 0,94 & 0,96 & 1,02 & 1,04 \\
\hline Milho (8\%) & 45,200 & 58,050 & 76,900 & 74,300 \\
\hline Farelo de soja (45\%) & 0,850 & 4,300 & 12,800 & 21,200 \\
\hline Farinha de carne e ossos $(50 \%)$ & 8,000 & 8,000 & 7,000 & - \\
\hline Farinha de sangue & 2,800 & 2,000 & - & - \\
\hline Farinha arroz integral & 40,000 & 25,00 & - & - \\
\hline Gordura suína & 1,350 & 0,650 & - & - \\
\hline Fosfato bicálcico & - & 0,130 & 0,638 & 2,290 \\
\hline Calcário calcítico (38\%) & 0,120 & 0,050 & - & 0,527 \\
\hline Sal & 0,230 & 0,250 & 0,300 & 0,400 \\
\hline Supl. Mineral-Vitamínico ${ }^{1}$ & 0,100 & 0,100 & 0,100 & 0,100 \\
\hline L-Lisina $\mathrm{HCl}$ & 0,396 & 0,427 & 0,495 & 0,437 \\
\hline L-Treonina & 0,200 & 0,203 & 0,210 & 0,169 \\
\hline DL-Metionina & 0,163 & 0,165 & 0,162 & 0,134 \\
\hline Inerte (caulim) & 0,556 & 0,640 & 1,360 & 0,408 \\
\hline Ractopamina & 0,025 & 0,025 & 0,025 & 0,025 \\
\hline Fitase & 0,010 & 0,010 & 0,010 & 0,010 \\
\hline \multicolumn{5}{|l|}{ Composição nutricional $^{2}$} \\
\hline Energia Metabolizável (kcal/kg) & 3.237 & 3.237 & 3.237 & 3.237 \\
\hline Proteína Bruta (\%) & 16,500 & 16,500 & 16,500 & 16,500 \\
\hline Lisina digestível (\%) & 0,940 & 0,960 & 1,020 & 1,040 \\
\hline Treonina digestível (\%) & 0,650 & 0,670 & 0,700 & 0,700 \\
\hline Met+Cistina digestível (\%) & 0,570 & 0,590 & 0,610 & 0,620 \\
\hline Triptofano digestível (\%) & 0,120 & 0,120 & 0,120 & 0,150 \\
\hline Cálcio (\%) & 0,900 & 0,900 & 0,910 & 0,890 \\
\hline Fósforo disponível (\%) & 0,610 & 0,610 & 0,610 & 0,610 \\
\hline Ractopamina (ppm) & 5 & 5 & 5 & 5 \\
\hline
\end{tabular}

${ }^{1}$ Conteúdo/kg de dieta; ${ }^{2}$ Composição calculada com base nas informações contidas em Rostagno et al. (2005). 
Os parâmetros de desempenho avaliados foram o consumo de ração diário, ganho de peso diário $\mathrm{e}$ a conversão alimentar. Foram realizadas pesagens dos animais, das rações e das sobras de ração, no início e no final do período experimental. Realizou-se a coleta diária do resíduo de ração do chão que foi somado as sobras de ração ao término do período experimental. A conversão alimentar foi calculada pela relação entre o consumo de ração e o ganho de peso.

Ao final do experimento todos os animais foram submetidos a jejum de sólidos de seis horas e transportados por $251 \mathrm{~km}$ até o frigorífico, onde permaneceram em baia de descanso por 10 horas com acesso livre à água. Por ocasião do abate, os suínos foram insensibilizados por eletronarcose e, posteriormente, sangrados, escaldados e eviscerados. As carcaças foram pesadas e tipificadas. As variáveis de rendimento de carcaça, carne magra e índice de bonificação foram calculados conforme metodologia proposta por Guidoni (2000).

Os dados obtidos foram submetidos à análise de variância, utilizando-se $\mathrm{o}$ peso inicial dos animais como covariável, pelo procedimento GLM do programa estatístico SAS Institute (1999), ao nível de 5\% de significância. As estimativas do melhor nível de lisina digestível foram determinadas por meio de análises de regressão linear, quadrática e o modelo descontínuo Linear Response Plateau, conforme o melhor ajuste obtido para cada variável estudada com base na menor soma dos quadrados dos desvios e/ou maior coeficiente de determinação.

\section{RESULTADOS E DISCUSSÃO}

Constatou-se redução linear $(\mathrm{P}<0,05)$ do consumo de ração diário de acordo com o aumento da concentração de lisina digestível na dieta (Figura 1; Tabela 2). Esse resultado está de acordo com o observado por Webster et al. (2007), que verificaram que suínos alimentados com dietas contendo níveis de lisina e ractopamina, tiveram o consumo voluntario de alimentos reduzido. Todavia, tem sido reportado na literatura que a concentração de lisina digestível não influencia o consumo de ração diário dos suínos machos não castrados (GASPAROTTO et al., 2001), machos castrados (ABREU et al., 2007) e fêmeas (FONTES et al., 2000; FORTES 2012). Porém, o aumento na densidade de lisina das dietas pode afetar a magnitude com que os suínos respondem a suplementação de ractopamina, e estar associado com a redução no consumo voluntário de alimento, sem prejuízos no ganho de peso e na eficiência alimentar (APPLE et al., 2004; WEBSTER et al., 2007). Esta interferência pode estar relacionada com a ação dos $\beta$-adrenérgicos sobre o ganho de peso e o perfil de aminoácidos depositados na massa muscular (REEDS \& MERSMANN, 1991).

A redução do consumo de ração, encontrada no presente estudo, também foi observada por Oliveira et al. (2003 a,b) e Fontes et al. (2005) que relataram redução no consumo de ração de acordo com o aumento do nível de lisina, porém em dietas isentas de ractopamina. Entretanto, outros pesquisadores avaliando suínos em fase de crescimento (ABREU et al., 2007; SERAO et al., 2012), terminação (CLINE et al., 2000) e terminação tardia (BATISTA et al., 2011; SANTOS et al., 2011) não constataram efeitos dos níveis de lisina sobre o 
consumo de ração em dietas isentas de ractopamina.

De modo similar, Pereira et al. (2008) avaliaram leitoas em terminação com dietas contendo 0 e $5 \mathrm{ppm}$ de ractopamina e 0,67 e $0,87 \%$ de lisina digestível e não constataram interação entre os fatores avaliados sobre $\mathrm{o}$ consumo de ração. Também Almeida et al. (2010) não verificaram efeito dos níveis de lisina digestível sobre o consumo de ração em dietas contendo 5 ppm de ractopamina.

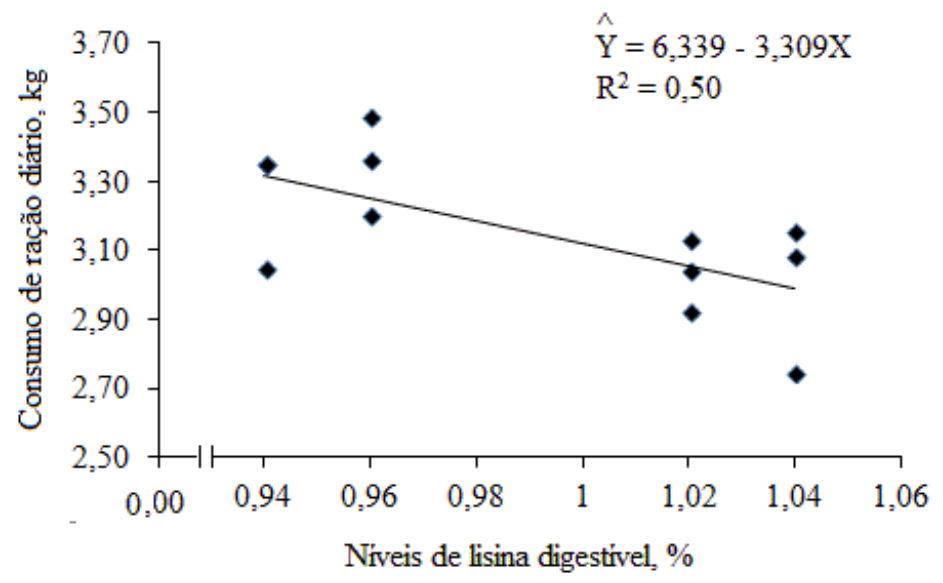

Figura 1. Consumo de ração diário de suínos em fase de terminação submetidos a dietas contendo diferentes níveis de lisina digestível em dietas contendo ractopamina. (Daily feed intake of pigs in the finishing phase submitted at diets with different levels of lysine in diets with ractopamine)

Tabela 2. Desempenho de suínos em terminação submetidos a dietas contendo diferentes níveis de lisina digestível e suplementados com ractopamina. (Performance of finishing pigs feeding with diets with different levels of digestible lysine and supplemented with ractopamine)

\begin{tabular}{|c|c|c|c|c|c|c|}
\hline \multirow{2}{*}{ Variáveis } & \multicolumn{4}{|c|}{ Níveis de lisina digestível (\%) } & \multirow{2}{*}{ Valor P } & \multirow{2}{*}{$\begin{array}{l}\text { CV } \\
(\%)\end{array}$} \\
\hline & 0,94 & 0,96 & 1,02 & 1,04 & & \\
\hline Peso inicial $(\mathrm{kg})$ & 81,26 & 82,41 & 86,00 & 84,88 & - & - \\
\hline Consumo de ração diário $(\mathrm{kg})^{*}$ & 3,25 & 3,35 & 3,03 & 2,99 & 0,019 & 5,22 \\
\hline Consumo de lisina diário (g) & 30,53 & 32,13 & 30,92 & 31,12 & 0,372 & 2,49 \\
\hline Ganho de peso diário $(\mathrm{kg})$ & 0,90 & 1,10 & 0,99 & 1,05 & 0,359 & 9,53 \\
\hline Conversão alimentar* & 3,62 & 3,03 & 3,06 & 2,84 & 0,009 & 7,56 \\
\hline Peso final $(\mathrm{kg}) *$ & 106,38 & 113,34 & 113,75 & 114,36 & 0,032 & 3,04 \\
\hline
\end{tabular}

*Efeito linear $(\mathrm{P}<0,05)$.

Embora se tenha observado redução linear do consumo de ração, o consumo de lisina digestível diário não foi influenciado $(\mathrm{P}>0,05)$ pelos níveis de lisina na dieta. Este resultado corrobora os achados de Marinho et al. (2007), que também não encontraram efeito dos níveis de lisina, em dietas contendo 5 
ppm de ractopamina, sobre o consumo de lisina digestível diário. Porém pesquisadores como Arouca et al. (2004) e Batista et al. (2011) relatam aumento do consumo de lisina digestível diário em função do aumento dos níveis de lisina digestível nas dietas. Provavelmente, no presente estudo, não foi observado efeito sobre o consumo de lisina diário em razão da redução do consumo de ração e pela pequena variação de lisina digestível entre os tratamentos.

Os níveis de lisina digestível não influenciaram $(\mathrm{P}>0,05)$ o ganho de peso diário dos animais. Resultado similar para ganho de peso diário foram obtidos por Oliveira et al. (2003 a, b) ao avaliarem níveis de lisina em dietas de suínos em fase de terminação tardia. Por outro lado, Santos et al. (2011) verificaram efeito significativo para o ganho de peso diário em função dos níveis de lisina na dieta dos suínos em terminação, sendo o nível recomendado de $0,803 \%$, correspondente ao consumo de lisina digestível diário de 24,60g.
A lisina apresenta função exclusiva de deposição de proteína corporal (CORRÊA et al., 2007), desta forma esperava-se encontrar efeito positivo sobre o ganho de peso diário dos animais recebendo dietas com níveis crescentes deste aminoácido, uma vez que a inclusão de ractopamina na dieta dos animais modifica o metabolismo aumentando a síntese de proteína muscular em detrimento a deposição de gordura (ARMSTRONG et al., 2004). A deposição do tecido proteico por agregar mais moléculas de água em relação à deposição de lipídios, pode resultar no aumento do ganho de peso dos suínos (HALAS et al., 2010).

O aumento dos níveis de lisina digestível das dietas proporcionou melhora linear $(\mathrm{P}<0,05)$ da conversão alimentar dos suínos (Figura 2). Observou-se neste estudo, que houve melhora de $27,5 \%$ na conversão alimentar com o nível de 1,04\% em relação ao tratamento com menor nível de lisina digestível.

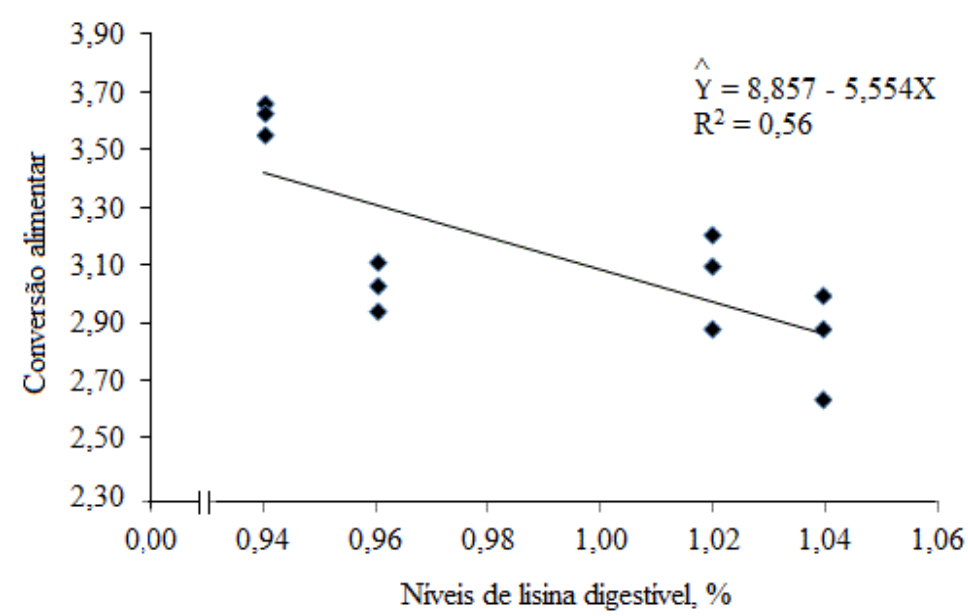

Figura 2. Conversão alimentar de suínos em fase de terminação submetidos a dietas contendo diferentes níveis de lisina digestível em dietas contendo ractopamina. (Feed conversion of pigs in the finishing phase submitted at diets with different levels of lysine in diets with ractopamine) 
De acordo com os resultados obtidos, pode-se inferir que os suínos alimentados com dietas contendo ractopamina e suplementados com maiores níveis de lisina digestível podem apresentar sua eficiência na utilização dos nutrientes aumentada, o que também foi observado por Marinho et al. (2007), Webster et al. (2007) e Pereira et al. (2008).
Apesar de não se ter obtido efeito sobre o ganho de peso diário no presente estudo, o peso final foi influenciado $(\mathrm{P}<0,05)$ pelos tratamentos, em que se observou aumento linear de peso final dos suínos de acordo com o aumento dos níveis de lisina digestível das dietas (Figura 3).

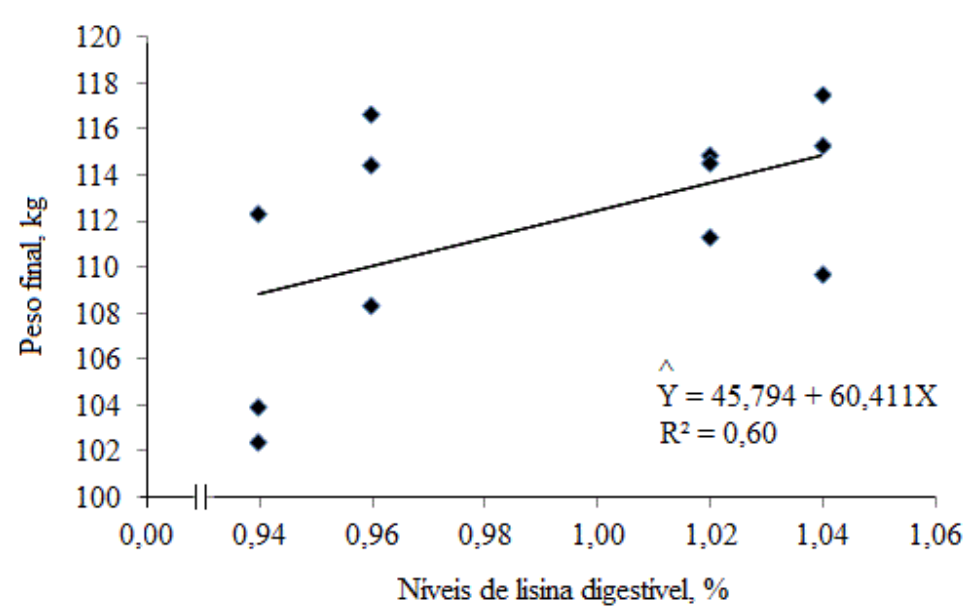

Figura 3. Peso final de suínos em fase de terminação submetidos a dietas contendo diferentes níveis de lisina digestível em dietas contendo ractopamina. (Final weight of pigs in the finishing phase submitted at diets with different levels of lysine in diets with ractopamine)

Aumento no peso final de $4,28 \%$ ou, o equivalente a $5,4 \mathrm{~kg}$ de carne por carcaça, foi observado por Pereira et al. (2008), quando alimentaram leitoas em terminação com dietas contendo $5 \mathrm{ppm}$ de ractopamina e $0,87 \%$ de lisina digestível. Aumentos do peso de abate também foram constatados por Marinho et al. (2007) para suínos machos castrados em terminação suplementados com $5 \mathrm{ppm}$ de ractopamina, porém não verificaram efeito com suplementação de lisina digestível até o nível de $0,87 \%$. Verificou-se efeito $(\mathrm{P}<0,05)$ dos tratamentos sobre o peso de frigorífico, que aumentou linearmente de acordo com o aumento dos níveis de lisina das dietas (Figura 4; Tabela 3). Esse resultado está coerente com a resposta observada para o peso final dos animais em que aqueles que obtiveram maior peso final apresentaram maior peso de frigorífico.

Não foi observado efeito $(\mathrm{P}>0,05)$ dos tratamentos sobre a perda de peso durante o transporte. No entanto, o peso de carcaça quente foi influenciado $(\mathrm{P}<0,05)$ pela inclusão de lisina nas dietas, que aumentou linearmente conforme o aumento dos níveis de lisina (Figura 5). Observou-se um incremento de $8,43 \mathrm{~kg}$ para o peso das carcaças dos animais alimentados com o nível de $1,04 \%$ de lisina digestível em relação ao tratamento com menor nível de lisina digestível. Esse resultado também está 
coerente ao observado para o peso final dos animais.

$\mathrm{O}$ rendimento de carcaça aumentou lineamente $(\mathrm{P}<0,05)$ em função dos níveis de lisina digestível das dietas (Figura 6). Conforme Schinkel et al. (2001), quando a ractopamina é administrado, a deposição de tecido muscular na carcaça aumenta numa proporção maior do que o crescimento dos órgãos viscerais, de maneira que há aumento do rendimento de carcaça. $\mathrm{O}$ melhor rendimento de carcaça foi obtido, no presente estudo, com o nível de $1,04 \%$ de lisina digestível, que apresentou rendimento de 3,44\% superior ao tratamento com $0,94 \%$ de lisina digestível.

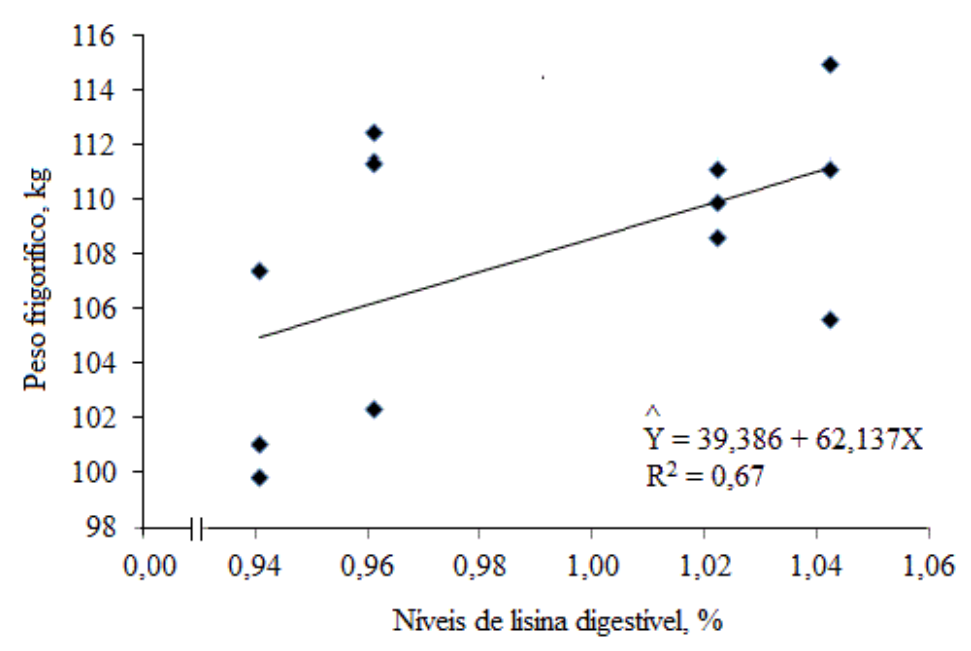

Figura 4. Peso de frigorífico de suínos de suínos em fase de terminação submetidos a dietas contendo diferentes níveis de lisina digestível em dietas contendo ractopamina. (Weight of swine slaughterhouse pigs in the finishing phase, submitted at diets with different levels of lysine in diets with ractopamine)

Tabela 3. Características de carcaça de suínos em terminação submetidos a dietas contendo diferentes níveis de lisina digestível e suplementados com ractopamina. (Carcass characteristics of finishing pigs feeding with diets containing different digestible lysine levels and supplemented with ractopamine.)

\begin{tabular}{|c|c|c|c|c|c|c|}
\hline \multirow{2}{*}{ Variáveis } & \multicolumn{4}{|c|}{ Níveis de lisina digestível, \% } & \multirow{2}{*}{ Valor P } & \multirow{2}{*}{$\begin{array}{l}\mathrm{CV} \\
(\%)\end{array}$} \\
\hline & 0,94 & 0,96 & 1,02 & 1,04 & & \\
\hline Peso frigorífico, $\mathrm{kg}^{*}$ & 102,92 & 108,81 & 110,0 & 110,65 & 0,017 & 2,80 \\
\hline Perda de peso, $\%$ & 3,22 & 4,03 & 3,29 & 3,25 & 0,694 & 31,0 \\
\hline Peso de carcaça, kg* & 75,49 & 80,39 & 82,70 & 83,92 & 0,005 & 3,46 \\
\hline Rendimento de carcaça, \%* & 73,32 & 73,87 & 75,18 & 75,84 & 0,009 & 1,43 \\
\hline Carne magra, $\%$ & 55,01 & 55,21 & 55,10 & 55,17 & 0,924 & 1,76 \\
\hline Carne magra, $\mathrm{kg}^{*}$ & 41,54 & 44,34 & 45,57 & 46,27 & 0,005 & 3,47 \\
\hline Bonificação, \%* & 100,2 & 101,8 & 102,35 & 102,77 & 0,021 & 1,07 \\
\hline
\end{tabular}

*Efeito linear $(\mathrm{P}<0,05)$. 


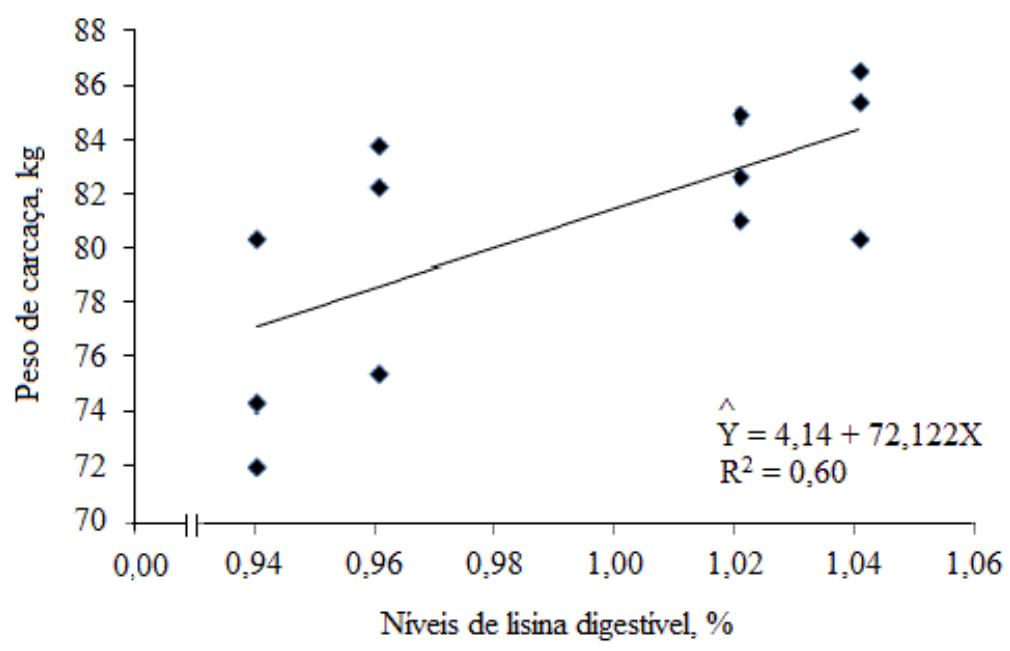

Figura 5. Peso de carcaça de suínos de suínos em fase de terminação submetidos a dietas contendo diferentes níveis de lisina digestível em dietas contendo ractopamina. (Carcass weight of pigs from pigs in the finishing phase submitted at diets with different levels of lysine in diets with ractopamine)

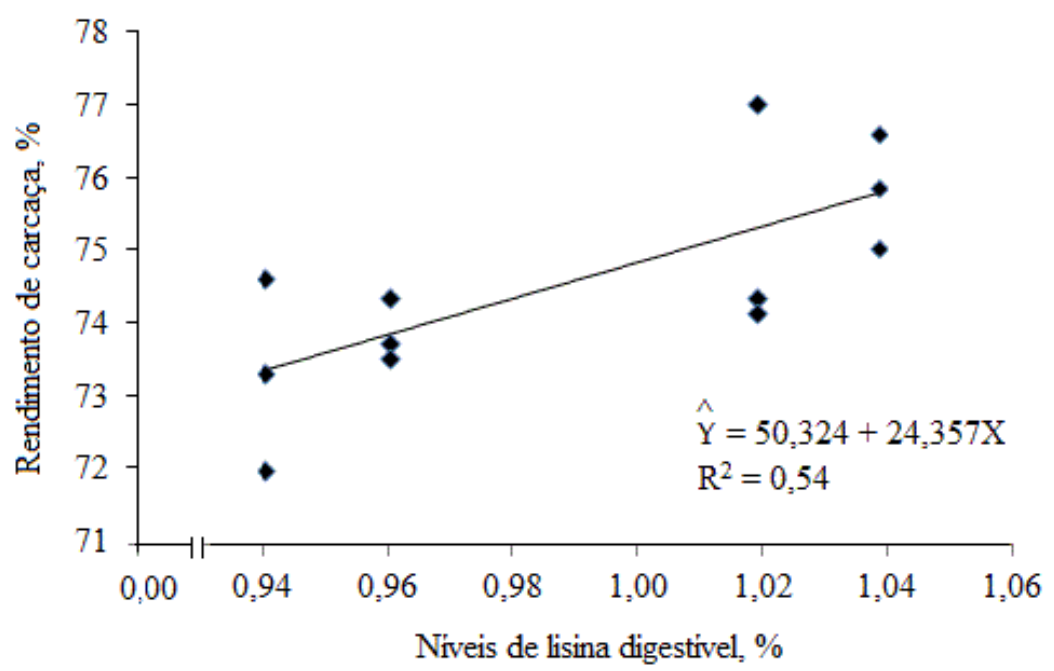

Figura 6. Rendimento de carcaça de suínos de suínos em fase de terminação submetidos a dietas contendo diferentes níveis de lisina digestível em dietas contendo ractopamina. (Carcass yield of pork from pigs in the finishing phase submitted at diets with different levels of lysine in diets with ractopamine)

Aumento do rendimento de carcaça proporcionado pelos níveis de ractopamina da dieta também foram obtidos por Armstrong et al. (2004), See et al. (2004) e Carr et al. (2005). Por outro lado, Pereira et al. (2008) não observaram efeito dos níveis de ractopamina sobre o rendimento de carcaça. 
Os níveis de lisina digestível das dietas não influenciaram $(\mathrm{P}>0,05) \quad \mathrm{a}$ porcentagem de carne magra dos suínos, que apresentaram valor percentual médio de $55,12 \%$. Apesar de não significativo estes valores estão próximos aos encontrados na literatura, conforme os resultados apresentados por Webster et al. (2007) que apresentaram valores médios de $54,45 \%$ para as dietas contendo 5 ppm de ractopamina e quatro níveis de inclusão de lisina digestível. Stoller et al. (2003) observaram que a suplementação de $10 \mathrm{ppm}$ de ractopamina à dieta não melhorou a porcentagem de carne magra na carcaça. Estudos de Corassa et al. (2010) não apontaram efeitos da inclusão de 5 e 10 ppm de ractopamina sobre o percentual de carne magra de machos castrados em fase de terminação tardia, que alcançaram em média 52,32\%. Valores superiores foram obtidos por Marinho et al. (2007), que obtiveram
57,3\% para suplementação com 5ppm de ractopamina sem aporte extra de lisina digestível.

Por outro lado, aumentos significativos de 1,$3 ; 1,5$ e $3,5 \%$ na porcentagem de carne magra foram observados por Sanches et al. (2010) quando suplementaram as dietas de suínos em terminação com 5; 10 e 20ppm de ractopamina, respectivamente, provavelmente geradas pela redução da lipogênese e aumento na síntese protéica.

Embora não tenha ocorrido efeito dos níveis de lisina digestível sobre o percentual de carne magra, verificou-se aumento linear $(\mathrm{P}<0,05)$ da quantidade de carne na carcaça, de acordo com o aumento dos níveis de lisina das dietas (Figura 7). Esse resultado pode ser explicado pelo aumento linear observado para o peso de carcaça quente em função dos níveis de lisina das dietas.

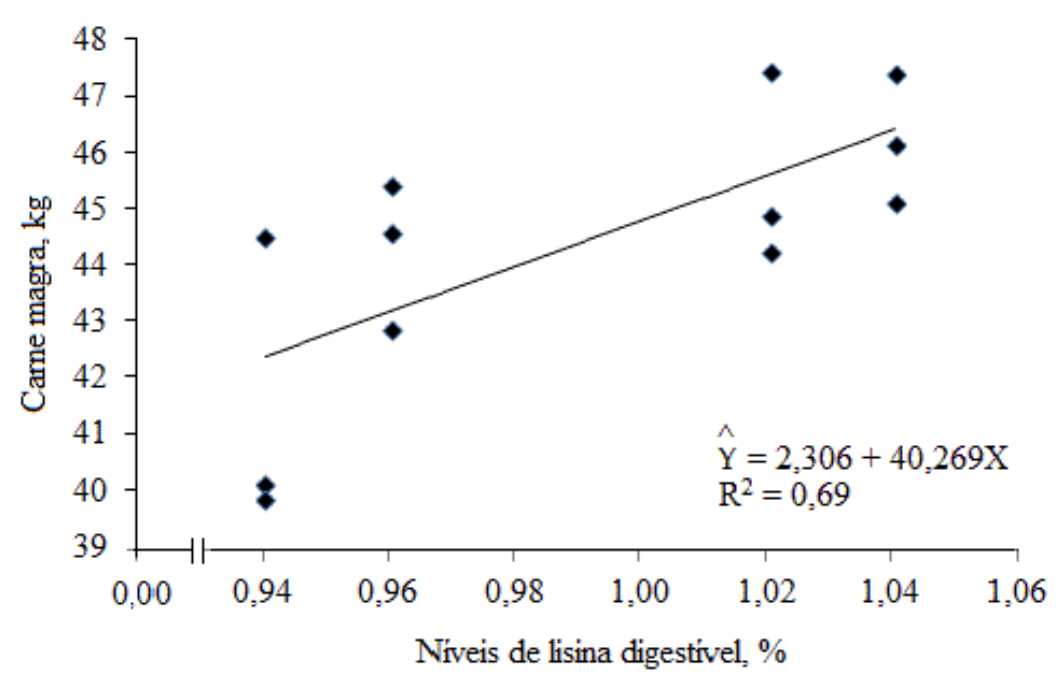

Figura 7. Carne magra de suínos de suínos em fase de terminação submetidos a dietas contendo diferentes níveis de lisina digestível em dietas contendo ractopamina. (Lean meat of pigs from pigs in the finishing phase submitted at diets with different levels of lysine in diets with ractopamine) 
A utilização de dietas com ractopamina e níveis de lisina tem sido relatada por melhorar a deposição de proteína na carcaça (WEBSTER et al. 2007; KIEFER \& SANCHES, 2009). Essa ação ocorre devido ao aumento da síntese de proteína muscular ou pela diminuição da sua degradação, sendo que a degradação da proteína é mediada pela atividade das proteases presente no músculo. Há evidencias que em animais tratados com ractopamina a atividade das proteases diminui por um incremento na concentração de inibidores proteolíticos (SPURLOCK et al., 1993).

Ao avaliarem níveis de lisina digestível sem a inclusão de ractopamina, para fêmeas em terminação, Cline et al. (2000) também observaram aumento linear na quantidade de carne na carcaça dos animais em função do aumento dos níveis de lisina digestível. Por outro lado, os valores obtidos para a quantidade de carne magra no presente estudo, estão abaixo dos observados por Santos et al. (2011) quando avaliaram níveis de lisina digestível em dietas isentas de ractopamina, para machos castrados dos 95 aos $125 \mathrm{~kg}$.

$\mathrm{O}$ índice de bonificação das carcaças foi influenciado $(\mathrm{P}<0,05)$ pelo aumento dos níveis de inclusão da lisina digestível nas dietas (Figura 8).

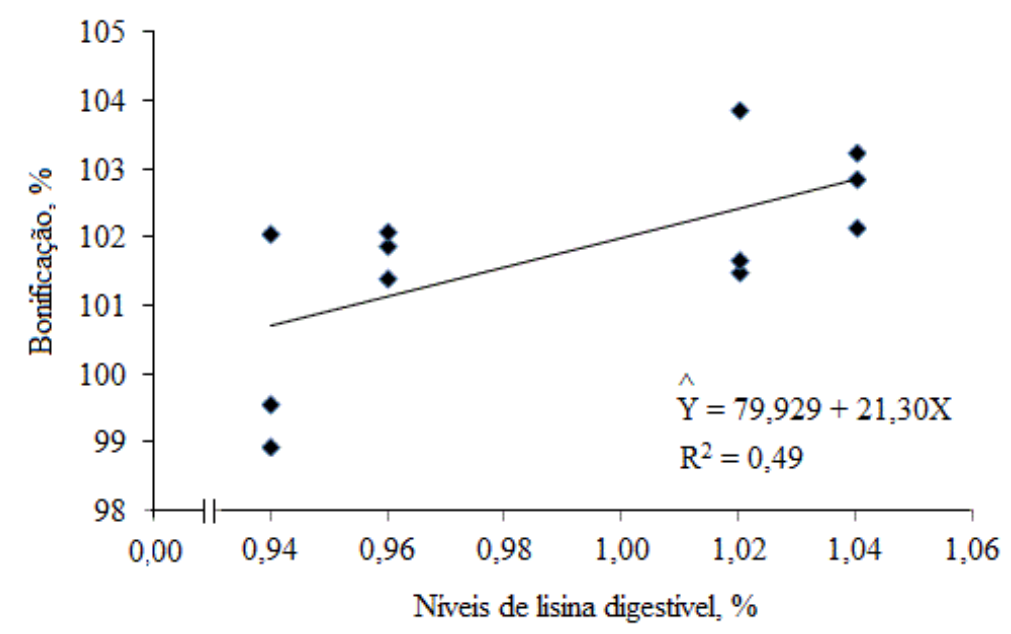

Figura 8. Bonificação de suínos em fase de terminação submetidos a dietas contendo diferentes níveis de lisina digestível em dietas contendo ractopamina. (Bonus pork from pigs in the finishing phase submitted at diets with different levels of lysine in diets with ractopamine)

O índice de bonificação das carcaças é uma variável de grande importância para os criadores, uma vez que está diretamente relacionada com a remuneração. No presente estudo, as carcaças dos suínos alimentados com dietas contendo $1,04 \%$ de lisina digestível alcançaram bonificação de $2,57 \%$ superior ao tratamento com $0,94 \%$ de lisina digestível. Estudos conduzidos por Sanches et al. (2010) também demonstraram melhorara em 1,0 e 2,3\% no índice de bonificação das carcaças de suínos cujas dietas foram 
suplementadas com 5 e 20ppm de ractopamina, respectivamente. Cantarelli et al. (2009) obtiveram 3,9\% de melhora da bonificação quando suplementaram os suínos com dietas contendo 5ppm de ractopamina e $1,04 \%$ de lisina digestível. Com base nos resultados obtidos, observou-se que a utilização de $\beta$-adrenérgicos associados a aportes extras de lisina digestível na dieta melhoraram a qualidade das carcaças dos suínos, proporcionando $\mathrm{o}$ atendimento das exigências do sistema de tipificação de carcaça atualmente utilizado no Brasil. Esta estratégia pode proporcionar melhor remuneração aos produtores por aumentar o índice de bonificação das carcaças.

De acordo com os resultados obtidos, no presente estudo, pode-se inferir que, em dietas contendo $5 \mathrm{ppm}$ de ractopamina, o nível de $1,04 \%$ de lisina digestível possibilita melhora do desempenho e das principais características de carcaça. $\mathrm{O}$ nível ótimo de $1,04 \%$ de lisina digestível estabelecido no presente estudo está $20 \%$ acima das recomendações de Rostagno et al. (2011), considerando-se o acréscimo de $0,123 \%$ de lisina digestível na exigência dos suínos quando alimentados com dietas contendo $5 \mathrm{ppm}$ de ractopamina.

A melhora das respostas de desempenho e dos parâmetros de carcaças observados no presente estudo utilizando-se níveis de lisina superiores as exigências estabelecidas nas tabelas de exigências nutricionais (ROSTAGNO et al., 2005; ROSTAGNO et al., 2011) estão de acordo com as recomendações de Mitchell et al. (1991) que preconizaram $30 \%$ a mais de lisina digestível em dietas contendo suplementação de ractopamina.

Recomenda-se o nível de $1,04 \%$ de lisina digestível, em dietas suplementadas com $5 \mathrm{ppm}$ de ractopamina, para suínos em terminação criados em lotes mistos.

\section{REFERÊNCIAS}

ABREU, M.L.T.; DONZELE, J.L.; OLIVEIRA, R.F.M.; OLIVEIRA, A.L.S.; HAESE, D.; PEREIRA, A.A. Níveis de lisina digestível em rações, utilizando-se o conceito de proteína ideal, para suínos machos de alto potencial genético, dos 30 aos $60 \mathrm{~kg}$. Revista Brasileira de

Zootecnia, v.36, p.62-67, 2007.

ALMEIDA, E.C.; FIALHO, E.T.; RODRIGUES, P.B.; ZANGERONIMO, M.G.; LIMA, J.A.F.; FONTES, D.O.

Ractopamine and lysine levels on performance and carcass characteristics of finishing pigs. Revista Brasileira de Zootecnia, v.39, p.1961-1968, 2010.

APPLE, J.K.; MAXWELL, C.V.; BROWN, D.C.; FRIESEN, K.G.; MUSSER, R.E.; JOHNSON, Z.B.; ARMSTRONG, T.A. Effects of dietary lysine and energy density on performance and carcass characteristics of finishing pigs fed ractopamine. Journal of Animal Science, v.82, p.3277-3287, 2004.

ARMSTRONG, T.A.; IVERS, D.J.; WAGNER, J.R.; ANDERSON, D.B.; WELDON, W.C.; BERG, E.P. The effect of dietary ractopamine concentration and duration of feeding on growth performance, carcass characteristics, and meat quality of finishing pigs. Journal of Animal Science, v.82, p.3245-3253, 2004.

AROUCA, C.L.C.; FONTES, D.O.; FERREIRA, W.M.; SILVA, M.A.; PEREIRA, F.A. Exigências de lisina, com base no conceito de proteína ideal, para suínos machos castrados, de 95 a $122 \mathrm{~kg}$, selecionados para deposição de carne magra. Arquivo Brasileiro de Medicina Veterinária e Zootecnia, v.56, p.773-781, 2004. 
BATISTA, R.M.; OLIVEIRA, R.F.M.; DONZELE, J.L.; OLIVEIRA, W.P.; LIMA, A.L.; ABREU, M.L.T. Lisina digestível para suínos machos castrados de alta deposição de carne submetidos a estresse por calor dos 30 aos $60 \mathrm{~kg}$.

Revista Brasileira de Zootecnia, v.40, p.1925-1932, 2011.

CANTARELLI, V.S.; FIALHO, E.T.; ALMEIDA, E.C.; ZANGERONIMO, M.G.; AMARAL, N.O.; LIMA, J.A.F. Características da carcaça e viabilidade econômica do uso de cloridrato de ractopamina para suínos em terminação com alimentação à vontade ou restrita.

Ciência Rural, v.39, p.844-851, 2009.

CARR, S.N.; IVRES, D.J.;

ANDERSON, D.B.; JONES, D.J.; MOWREY D.H.; ENGLAND, M.B.; KILLEFER, J.; RINCKER, P.J.; MCKEITH, F.K. The effects of ractopamine hydrochloride on lean carcass yields and pork quality characteristics. Journal of Animal Science, v.83, p.2886-2893, 2005.

CLINE, T.R.; CROMWELL, G.L.; CRENSHAW, T.D.; EWAN, R.; HAMILTON, C.R.; LEWIS, A.J.; MAHAN, D.C.; SOUTHERN, L.L. Further assessment of the dietary lysine requirement of finishing gilts. Journal of Animal Science, v.78, p.987-992, 2000 .

CORASSA, A.; LOPES, D.C.; TEIXEIRA, A.O. Desempenho, características de carcaça e composição óssea de suínos alimentados com diferentes níveis de ractopamina e fitase. Revista Brasileira de Zootecnia, v.39, p.1740-1747, 2010.

CORRÊA, G.S.S.; SILVA, M.A.; CORRÊA, A.B.; FONTES, D,O; SANTOS, G.G.; DIONELLO, N.L.; WENCESLAU, R.R.; FELIPE, V.P.S.;
FERREIRA, I.C.; SOUSA, J.E.R. Desempenho de codornas de corte EV1 alimentadas com diferentes níveis de lisina na dieta. Arquivo Brasileiro de Medicina Veterinária e Zootecnia, v.59, p.1545-1553, 2007.

FONTES, D.O.; DONZELE, J.L.; OLIVEIRA, R.F.M.; LOPES, D.C.; FERREIRA, A.S.; , SILVA, F.C.O. Níveis de lisina para leitoas selecionadas geneticamente para deposição de carne magra na carcaça, dos 30 aos $60 \mathrm{~kg}$. Revista Brasileira de Zootecnia, v.34, p.81-89, 2005.

FONTES, D.O.; DONZELE, J.L.; OLIVEIRA, R.F.M.; CONHALATO, G.S.; PEREIRA, M.A. Níveis de lisina para leitoas selecionadas geneticamente para deposição de carne magra, dos 30 aos $60 \mathrm{~kg}$, mantendo constante a relação entre lisina e metionina + cistina, treonina, triptofano, isoleucina e valina. Revista Brasileira de Zootecnia, v.29, p.776-783, 2000.

FORTES, E.I.; DONZELE, J.L.; OLIVEIRA, R.F.M.; SARAIVA, A.; SILVA, F.C.O.; SOUZA, M.F. Sequências de lisina digestível para suínos de duas linhagens selecionadas para alta deposição de carne. Revista Brasileira Saúde e Produção Animal [online], v.13, p.480-490, 2012.

GASPAROTTO, L.F.; IVAN MOREIRA, I.; FURLAN, A.C.; MARTINS, E.M.; JÚNIOR, M.M. Exigência de lisina, com base no conceito de proteína ideal, para suínos machos castrados de dois grupos genéticos, na fase de crescimento.

Revista Brasileira de Zootecnia, v.30, p.1742-1749, 2001.

GUIDONI, A.L. Melhoria de processos para a tipificação e valorização de carcaças suínas no Brasil. In: 
CONFERENNCIA INTERNACIONAL VIRTUAL SOBRE QUALIDADE DE CARNE SUÍNA, 1. 2000, Concórdia. Anais... Concórdia: EMBRAPACNPSA, 2000. p.14.

HALAS, V.; BABINSZKY, L.; DIJKSTRA, J.; VERSTEGEN, M.W.A.; GERRITS, W.J.J. Efficiency of fat deposition from non-starch polysaccharides, starch and unsaturated fat in pigs. British Journal of

Nutrition, v.103, p.123-133. 2010.

KIEFER, K.; SANCHES, J.F.

Metanálise dos níveis de ractopamina em dietas para suínos em terminação.

Revista Brasileira Zootecnia, v.38, p.1037-1044, 2009.

MARINHO, P.C.; FONTES, D.O.; SILVA, F.C.O; SILVA, M.A; PEREIRA, F.A.P.; AROUCA, C.L.C. Efeito da ractopamina e de métodos de formulação de dietas sobre o desempenho e as características de carcaça de suínos machos castrados em terminação. Revista Brasileira de Zootecnia, v.36, p.1061-1068, 2007.

MILLS, S.E. Biological basis of the ractopamine response. Journal of Animal Science, v. 80, p.28-32, 2002.

MITCHELL, A.D; SOLOMON, M.B.; STEELE, N.C. Influence of level of dietary protein or energy on effects of ractopamine in finishing swine. Journal of Animal Science, v.69, p.4487-4495, 1991.

OLIVEIRA, A.L.S.; DONZELE, J.L.; OLIVEIRA, R.F.M.; LOPES, D.C.; MOITA, A.M.S.; SILVA, F.C.O.; FREITAS, L.S. Lisina para suínos machos castrados de alto potencial genético para deposição de carne magra dos 95 aos 110kg. Revista Brasileira de Zootecnia, v.32, p.337-343, 2003a.
OLIVEIRA, A.L.S.; DONZELE, J.L.; OLIVEIRA, R.F.M.; FERREIRA, A.S.; MOITA, A.M.S.; GENEROSO, R.A.R. Lisina em rações para suínos machos selecionados para deposição de carne magra na carcaça dos 110 aos $125 \mathrm{~kg}$. Revista Brasileira de Zootecnia, v.32, p.150-155, 2003b.

PEREIRA, F.A.; FONTES, D.O.; SILVA, F.C.O.; FERREIRA, W.M.; LANNA, A.M.Q.; CORREAA, G.S.S.; SILVA, M.A.; MARINHO, P.C.; AROUCA, C.L.C.; SALUM, G.M. Efeitos da ractopamina e de dois níveis de lisina digestível na dieta sobre o desempenho e características de carcaça de leitoas em terminação. Arquivo Brasileiro de Medicina Veterinária e Zootecnia, v.60, p.943-952, 2008.

PÉREZ, A.; OBISPO, N.E.; PALMA, J.P.; CHICCO, C.F. Efectos de La ractopamina y lisina sobre la deposición de grasa en cerdos seleccionados magros en la fase de engorde.

Zootecnia Tropical, v.24, p.435-455, 2006.

REEDS, P.J.; MERSMANN, H.J. Protein and energy requirements of animals treated with beta-adrenergic agonists: a discussion. Journal of Animal Science, v.69, p.1532-1550, 1991.

ROSTAGNO, H.S.; ALBINO, L.F.T.; DONZELE, J.L.; GOMES, P.C.; OLIVEIRA, R.F.; LOPES, D.C.; FERREIRA, A.S.; BARRETO, S.L.T.Tabelas Brasileiras para aves e suínos. Composição de alimentos e exigências nutricionais. 2 ed. Viçosa, MG: Universidade Federal de Viçosa, $2005.186 \mathrm{p}$. 
ROSTAGNO, H.S. ALBINO, L.F.T.; DONZELE, J.L.; GOMES, P.C.

OLIVEIRA, R.F.; LOPES, D.C.; FERREIRA, A.S.; BARRETO, S.L.T.; EUCLIDES, R.F. Tabelas Brasileiras para aves e suínos: composição de alimentos e exigências nutricionais. 3 ed. Viçosa, MG: Universidade Federal de Viçosa, 2011.252p.

SANCHES, J.F.; KIEFER, C.; MOURA, M.S.; SILVA, C.M.; LUZ, M.F.; CARRIJO, A.S. Niveis de ractopamina para suinos machos castrados em terminação e mantidos sob conforto térmico. Ciência Rural, v.40, p.403-408, 2010 .

SANTOS, F.A.; DONZELE, L.L.; SILVA, F.C.O.; OLIVEIRA, R.F.M.; ABREU, M.L.T.; SARAIVA, A.; HAESE, D.; LAZARINI LIMA, A.L. Níveis de lisina digestível para suínos machos castrados de alto potencial genético dos 95 aos $125 \mathrm{~kg}$.. Revista Brasileira de Zootecnia, v.40, p.10381044, 2011.

SAS Institute. Statistical Analysis System: user's guide : statistics. Cary, 1999.

SCHINCKEL, A.P.; RICHERT, B.T.; HERR, C.T., EINSTEIN, M.E.;

KENDALL, D.C. Efeitos da ractopamina sobre o crescimento, a composição da carcaça e a qualidade dos suínos. In: CONFERENCIA INTERNACIONAL VIRTUAL SOBRE QUALIDADE DA CARNE SUÍNA, 2., Foz do Iguaçu, Paraná . Anais... Foz do Iguaçu, Paraná, 2001. p.1-12.

SEE, M.T., ARMSTRONG, T.A.; WELDON, W.C. Effect of a ractopamine feeding program on growth performance and carcass composition in finishing pigs. Journal of Animal Science, v.82, p.2474-2480, 2004.
SERAO, M.C.; DONZELE, J.L.; SILVA, F.C.O.; OLIVEIRA, R.F.M.; FERREIRA, A.S.; KILL, J.L.; APOLÔNIO, L.R. Níveis de lisina digestível de fêmeas suínas selecionadas para deposição de carne magra na carcaça dos 30 aos $60 \mathrm{~kg}$. Revista Brasileira de Saúde e Produção Animal [online], v.13, p.433-443, 2012.

SPURLOCK, M.E.; CUSUMANO, J.C.; MILLS, E. The affinity of ractopamine, clenbuterol, and L644,969 for the beta-adrenergic receptor population in porcine adipose tissue and skeletal muscle membrane. Journal of Animal Science, v.71, p.2061-2065, 1993.

STOLLER, G.M.; ZERBY, H.N.; MOELLER, S.J.; BAAS, T.J.; JOHNSON, C.; WATKINS, L.E. The effect of feeding ractopamine (paylean) on muscle quality and sensory characteristics in three diverse genetic lines of swine. Journal of Animal Science, v.81, p.1508-1516, 2003.

WEBSTER, M.J.; GOODBAND, R.D.; PAS TOKACH, M.D.; NELSSEN J.L., DRITZ, S.S.; UNRUH, J.A.; BROWN, K.R.; REAL, D.E.; DEROUCHEY, J.M.; WOODWORTH, J.C.; GROESBECK, C.N.; MARSTELLER, T.A. Interactive Effects Between Ractopamine Hydrochloride and Dietary Lysine on Finishing Pig Growth Performance, Carcass Characteristics, Pork Quality, and Tissue Accretion.

The Professional Animal Scientist, v.23, p.597-611, 2007.

Data de recebimento: $25 / 01 / 2013$

Data de aprovação: 05/09/2013 